\title{
Michel Foucault y René Magritte: algunas afinidades electivas
}

\author{
Michel Foucault and René Magritte: \\ certain elective affinities
}

Daniel Gihovani Toscano López

Resumen

Este escrito, resalta no las diferencias sino las relaciones entre Magritte y Foucault. Se trata de atender a la posibilidad no sólo de suscitar un diálogo entre ambos personajes, sino de superar la lógica del sentido. Para esto, primero estudiaremos los conceptos de paradoja y rareza como rasgos característicos de ambos. Segundo, abordaremos la filosofía y el arte como cajas de herramientas para la reflexión. Tercero, analizaremos la afinidad entre palabra e imagen como un elemento importante en juego. Finalmente, efectuaremos una tematización de sus obras.

\section{Palabras clave}

Afinidades, paradoja, rareza, filosofía, arte, obras.

\section{Abstract}

This essay is not about the differences between Michel Foucault and René Magritte. It is about their relationships. We must attend to the possibility not only of stimulating a dialogue between both characters but also, and above all, of overcoming sense logic. In order to do this, first we study the concepts of paradox and rarity as characteristic features of both of them. Second, we must think of philosophy and art as toolkits for the reflection. Third, we will analyze the affinity between word and image as an important element at play here. Finally, we will perform a thematization of their works.

\section{Keywords}

Affinities, paradox, rarity, philosophy, art, works.

Artículo recibido el 30 de julio de 2009 y aprobado el 16 de octubre de 2009.

1 Pontificia Universidad Javeriana: Instituto Pensar, Grupo de Investigación Filosofía Política y Moral. Correo electrónico: dantoslopez@hotmail.com 
Desde la óptica del sentido común, entendido éste como la búsqueda de identidades fijas en medio de la abigarrada multiplicidad de las cosas, vano y estéril es tender un puente de comparación entre dos personajes que, por la particularidad de sus actividades, suscitan la sensación de ser polos contrapuestos. Uno francés y el otro belga. El primero filósofo, historiador y activista; el otro, un excéntrico pintor.

Foucault, nacido en el período de entre guerras en 1927 e influido por autores como Nietzsche, Merleau Ponty, Canguilhem, Bachelard, entre otros. Magritte, pintor de finales del siglo XIX, bebió de una variopinta fuente de inspiración proveniente de Edgar Allan Poe, Robert Louis Stevenson, Baudelaire, Duchamp, Heidegger y el mismo Hegel. Desde esta serie de consideraciones, a todas luces, puede sostenerse de forma categórica que el abismo que separa estas dos personalidades es insalvable. No obstante, la imposibilidad de rastrear algunas vecindades entre Foucault y Magritte, y de reparar con machacona insistencia en las diferencias que los separan, responde a la esquizofrénica tendencia de compararlo y filtrarlo todo desde la criba de la razón. Elementos que no sean ajustables a la infalible lógica del sentido son descalificados y marginados por ser catalogados como diferentes, excéntricos y aberrantes.

El presente escrito está animado por la idea según la cual existe una afinidad entre estos dos personajes, Foucault y Magritte. Dicho encuentro es provocado al hilo de cuatro categorías puestas de relieve y que, a continuación, abordaremos de manera pormenorizada: en primer lugar, la paradoja y la rareza como notas característica tanto de la filosofía de Foucault, como del arte de Magritte; en segundo lugar, la filosofía y el arte como oficios que dan que pensar; en tercer lugar, los juegos de relación entre la palabra y la imagen o lo enunciable y lo visible; en cuarto lugar, la caleidoscópica obra de ambos que, al resistirse a ser rotulada por una determinada perspectiva filosófica o artística, está sometida a rectificaciones, desplazamientos y reelaboraciones que, antes de mostrarla caduca o defectuosa, la abren hacia posibilidades inéditas.

\section{La paradoja y la rareza como notas características de sus oficios}

Ambos, tanto el filósofo de Poitiers como el pintor de Lessines, ejercitaron las herramientas de sus respectivos oficios sobre la trama compleja de lo visible.
Foucault, el filósofo, golpeará con el martillo de la investigación filosófica la dura capa cristalizada de lo evidente para convertirla en un problema. Magritte, el pintor, grabará en el lienzo, no un frívolo retrato de lo percibido como fenómeno incontrovertible, sino que lo alterará y recreará hasta inundarlo de poesía. Mientras el primero asesta un duro golpe al historicismo porque éste, al concebir los hechos históricos desde una lógica lineal y evolutiva, los empobrece hasta reducirlos a la figura del monumento, el segundo, va lanza en ristre contra la percepción tradicional de la realidad. Por esto es que "el propósito de Magritte es siempre sacar a la luz lo que queda oculto por lo visible" (Paquet, 2000, p. 55).

La filosofía del pensador francés incorpora en el seno de sus investigaciones diversos ámbitos y temas como la cultura, la historia, la locura, el Estado, la sociedad civil, las instituciones, el poder, entre otros, así como variados métodos entre los que se cuentan la arqueología, la genealogía y el nominalismo, lo cual suscita la impresión de un pensador cuyo periplo intelectual está sometido al vaivén de rupturas y rectificaciones. Tal sensación, de una investigación atomizada, nada compacta y coherente, labra la imagen de alguien que expone en sus obras una sarta de incongruencias y de ideas deshilvanadas que no conducen a parte alguna. Por eso, a tenor de estudiosos como Vásquez, algunos señalan con respecto a Foucault que "todavía más de uno se resiste a incluir en el panteón de los filósofos" (Vásquez, 1995, p. 11). Dicho prejuicio según el cual, el pensador francés dista de ser tenido en cuenta como filósofo, obedece al carácter discontinuo y difuso de su pensamiento que, lejos de ser un defecto o desventaja, es el efecto inmediato de un método que queda retratado en los cursos del Collège de France de 1979 en Nacimiento de la biopolítica: "soy como el cangrejo, me muevo lateralmente" (Foucault, 2007, p. 96). Lo cual subraya no sólo un modo extraño, raro, repetitivo y discontinuo de hacer filosofía, sino también paradójico.

La noción de paradoja ha de entenderse en el sentido Deleuziano como "lo que destruye la cordura como sentido único y, a continuación lo que destruye el sentido común como asignación de identidades fijas" (Deleuze, 1970, p. 12). En consecuencia, desde esta perspectiva, objetos de estudio como el Estado, el neoliberalismo, el gobierno, la población, entre otros, son para este pensador fenómenos a los que 
se les suele asumir como problemáticos e incontrovertibles, dotados de sentido propio. Desde la óptica de la historia oficial son datos naturales, con vida propia; sin embargo, el profesor del Collège de France, al sospechar de tales universales antropológicos genera una especie de giro copernicano en el que no son los objetos los que determinan las prácticas, sino que éstas y las discontinuidades son las que hacen posible dichos objetos.

Por otra parte, en las pinturas del artista belga vemos el despliegue de una viva tensión entre lo conocido y lo oculto 2 , el sentido y el sin sentido ${ }^{3}$, lo serio y lo misterioso ${ }^{4}$, lo revelado y lo secreto ${ }^{5}$, lo visible y lo legible 6 ; no obstante, en sus cuadros es imposible que se dé lo oculto o lo manifiesto a secas. Ahora bien, no es que en René Magritte deba hacerse hincapié en una suerte de ambigüedad nociva que atraviesa su producción pictórica. Antes bien, ese movimiento pendular, que va de lo visible a lo invisible, pone de relieve una obra elusiva, poliédrica, que se resiste a la racionalización, armonización y homogeneidad, así como a ser reducida a criterios dualistas.

La paleta del pintor Belga no está orientada por un principio rector o por una finalidad trascendente al mismo acto de pintar, pues no es lo pintado lo que justifica la práctica de pintar, sino a la inversa, la práctica, es decir, el deseo como afecto que circula en su heterogeneidad, lo que es grilla de inteligibilidad de sus pinturas. Ahora bien, al interrogar por el propósito que subyace a las telas de Magritte, no es un asunto al que se pueda responder de antemano al acto mismo de la creación artística, pues, tal y como se evidencia en sus escritos:

2 De este juego entre lo conocido y lo oculto pueden apreciarse pinturas como La gran guerra (1964), en la que el mismo Magritte comenta que "cada cosa que vemos cubre otra, y nos gustaría mucho ver lo que nos oculta lo visible" (Paquet, 2000, p. 14); Las flores del mal (1946); El bello mundo (1962); Firma en blanco (1965); Calcomanía (1966); Entreacto (1927-28); Los amantes (1928), entre otras.

3 En el fresco El hada ignorante, del Palacio de Bellas Artes en Bélgica, queda retratado el poder de la pintura en relación con el asunto del sentido y el sin sentido, "es dueña de poderes mágicos cuyo sentido desconoce. "El sentido es lo imposible", gustaba de repetir Magritte" (op. cit., p. 32).

4 Como en las obras El jockey perdido (1926) y El jugador secreto (1927).

5 Véase la pintura El imperio de las luces (1954).

6 Ver El arte de la conversación (1950).
Un gran error es la causa de las búsquedas desesperadas de la mayor parte de los pintores modernos: quieren fijar a priori el estilo-aspecto de un cuadro; ahora bien, este estilo es el resultado fatal de un objeto bien hecho: la unidad de la idea creadora y de su materialización (Magritte, 2003, p. 19).

Cuando en La llave de los sueños, el artista pinta diversos objetos acompañados de nombres que no les corresponden, presenta una pluralidad de elementos que no se perturban por no tener un origen o lógica común. De este modo, la clave en Magritte es la paradoja, del mismo modo que en Foucault:

Todo gira en torno a esa paradoja [...] lo que se ha hecho, el objeto, se explica por lo que ha sido el hacer en cada momento de la historia; es equivocada la idea que tenemos de que el hacer, la práctica, se explica a partir de lo que se ha hecho (Veyne, 1984, p. 215).

En efecto, las telas del pintor belga son raras de la misma manera en que los objetos y prácticas lo son desde la filosofía foucaultiana.

La noción de rareza fue empleada por George Ville y reactivada por el historiador Veyne (1984). El término en cuestión captura muy bien lo que descubre el método nominalista en historia trabajado por éstos, aunque seguido por el filósofo francés. La rareza es lo que Paul Veyne dio en llamar la "parte oculta del iceberg". Con el fin de ilustrar este punto, cuando el autor de Vigilar y castigar (1998) investiga cómo es que Occidente se ha constituido en una sociedad disciplinaria, y cómo es que se ha llegado a la formación de una tecnología disciplinaria, cuyo respaldo institucional es la prisión, se pregunta cómo es que ha llegado a existir una realidad que antes era impensable. En respuesta a esto, Foucault señala en la Entrevista sobre la prisión: el libro y su método que hubo un momento en que "se percibió que, para la economía del poder, era más eficaz y más rentable, vigilar que castigar" (Foucault, 1999, p. 298). En este orden de ideas, la empresa filosófica que acomete el filósofo de Poitiers consiste en situar las relaciones de poder de la prisión, así como del hospital psiquiátrico, la escuela o el taller en una “economía general del poder". Es decir, por detrás 
de la prisión y del asilo, descentrando el poder de una lectura institucional, las relaciones de poder se sitúan en una serie de estrategias y prácticas que configuran campos de verdad y generan objetos de saber.

Por práctica ha de entenderse lo que Habermas subraya, refiriéndose a Foucault, en el Discurso filosófico de la modernidad: "regulaciones de las formas de acción, y costumbres consolidadas institucionalmente, condensadas ritualmente, y a menudo materializadas en formas arquitectónicas" (Habermas, 1989, p. 291). De lo que se trata, entonces, es de quitar la vista de los objetos evidentes y obvios como el Estado, la sexualidad, la locura, la prisión para ponerla en prácticas menospreciadas que los cosifican. Tales prácticas, estrategias y tácticas de poder son invisibilizadas al modo en que la parte oculta de un iceberg es ignorada en el momento en que la vista se fija en la parte emergente. Las prácticas son desplazadas porque los objetos que se explican por éstas se tornan en monumentos del discurso oficial y, por ende, son adoptados como hechos evidentes y naturales. Tal ocultamiento de las prácticas obedece, en palabras de Dreyfus y Rabinow, a que en relación con el hombre: "éste no puede reflexionar sobre qué son las prácticas, precisamente porque están demasiado cerca de él y, por eso, son demasiado abarcadoras" (Hubert y Rabinow, 2001, p. 65).

En consecuencia, Foucault no parte de los hechos evidentes, sino que disuelve las apariencias al convertir lo dado en un problema. Así, en el lugar de lo incontrovertiblemente verdadero, viene a ocuparlo una práctica extraña, oculta, invisibilizada, rara y no vista. De aquí proviene la rareza. Esta misma ilusión, de concebir, por una parte, objetos como los gobernantes, el Estado, la infraestructura y, por otra, las prácticas que los engendran es el dualismo nefasto al que tanto Foucault se enfrenta desde la filosofía, como Magritte desde el arte.

Por su parte, la rareza en Magritte proviene de una devoción y de un culto al misterio ${ }^{7}$ de las cosas del mundo, y es el resultado de lo que el mismo pintor ha dado en llamar efecto poético, que puede evidenciarse en telas como El imperio de las luces,

7 Tres son los recuerdos infantiles que se gravan en la sensibilidad de Magritte: una caja junto a su cuna, un enorme globo desinflado en el techo de la casa de sus vecinos y los frecuentes juegos con una niña en un viejo cementerio. en el que el día y la noche no riñen entre sí, sino que causan, al ser evocados, sorpresa y fascinación. De allí que su oficio de pintor esté cargado de una actividad poética y que:

El objetivo perseguido por Magritte consistirá también en hacer sentir o percibir, por medio de una pintura que nos sorprende o nos fascina, el misterio inexplicable de la existencia, la misteriosa realidad que envuelve a los seres y a las cosas más allá de su finalidad utilitaria y más allá del orden habitual y racional que ocultan las dimensiones profundas del dinamismo secreto de la vida (Fernández, 2000, p. 51).

Refiriéndose al misterio de la existencia, del cual la pintura no puede más que evocar, en las cartas que Magritte envía a André Bosmans se puede leer que: "es estéril", "vacío", "sin contenido", "incapaz de cambiar nada para bien o para mal”. Está miserablemente reducido a ser el principio absoluto y necesario para que lo real pueda existir, para que "se puedan manifestar las cosas más irrisoriamente y las más sublimes" (Torczyner, 1978, p. 54). En otras palabras, no es que el misterio sea una especie de esencia o sustancia, instalado más allá de las cosas mismas, esperando a que sea descorrida la cortina de las apariencias para descubrirlo, antes bien, el hombre está siempre instalado en él, mientras que las cosas y el misterio son consustanciales. La razón humana nunca podrá conocer a ciencia cierta el misterio de la vida o de la muerte, pero sí evocarlo por medio de analogías y de imágenes de las que se sirve la imaginación y sensibilidad poética de la pintura.

\section{Filosofía y arte que detonan pensamiento}

Las pinturas de Magritte son una explosión de inquietud y reflexión, no desde la lógica de la razón, sino desde la lógica del misterio, mientras que en Foucault su investigación elusiva y a sistemática es una exigencia a pensar de otro modo, diferente a un pensamiento sistemático, ortodoxo y científico, que se parece a quien ve:

Un cachalote que salta por encima del agua y deja en ella una pequeña huella transitoria de espuma, y que permite creer, hace creer o quiere creer, o bien tal vez cree efectivamente que por debajo, 
donde ya no se lo ve, donde ya nadie lo percibe ni lo controla, sigue una trayectoria profunda coherente y meditada (Foucault, 2001, p. 27).

Como ya puede advertirse, nuestros dos personajes rehuyen a lo convencional sin sustraerse por ello de la realidad, porque, como lo manifiesta el propio pintor belga, en carta a Rapin del 2 de diciembre de 1957 (1978), él se declara un derrotista integral. Por su parte, el filósofo, en discusión con Habermas, se declara un pesimista hiperactivo. En este sentido, no podemos caer en sostener redondamente que ambos compartan una posición de escepticismo frente a la realidad, sino más bien, de sospecha frente a lo dado y de modos de abordarla desde una óptica diferente. Ambos escapan de lo inmediato y mediante el ejercicio del pensar se sustraen de lo visible para pensarlo desde una perspectiva distinta.

Tanto en Foucault como en Magritte, encontramos que sus obras son desconcertantes y perturbadoras hasta el punto que parece que nada queda en su lugar. En el primer caso, Salma Tannus, estudiosa del filósofo, cuando se refiere al talante crítico de Foucaul, termina dibujando un tipo de pensamiento que consiste en "pensar diferente de lo que se piensa y percibir diferente de lo que se ve" (Muchail, 2004, p. 20). A lo cual puede añadirse un ejercicio de reflexión de poder desprenderse de sí mismo con la finalidad de pensar en un asunto en el que no se pensaba antes. En el segundo caso, aludiendo al pintor belga, Handle, en su libro Museum of the Mind, sostiene: "Frustrando nuestras expectativas seguras, fastidiando, escandalizando y rechazándonos, Magritte sabe desestabilizar nuestro ambiente visual. Él puede hacernos sentir inseguridad" (Handler, 1994, p. 10). En sus pinturas recurre al contraste que lleva una imposibilidad a otra imposibilidad, como en Las vacaciones de Hegel (1958), en el que existen dos objetos enteramente distintos, uno que repele el agua y el otro que la recibe o, tal como se presenta en La llave de vidrio (1959), en el que la percepción de una roca riñe con las leyes de lo cotidiano, pues se ha suscitado en ésta la sensación de total ligereza. Es por esto que "en casi todas las telas de Magritte es posible observar casi siempre elementos en pugna que provocan un impacto que sacude violentamente nuestro espíritu y nos estimula a pensar" (Paquet, 2000, p. 15).
La figura que mejor retrata la investigación foucaultiana es la del cangrejo que se mueve lateralmente, que vuelve en sus investigaciones con machacona insistencia sobre asuntos que parecen trillados, cuyo periplo intelectual, lejos de ser homogéneo, lineal y continuo, está salpicado de rectificaciones y desviaciones. Por su parte, Magritte y su pintura son como el indio que: "da marcha atrás, desvía, disfraza sus huellas y se mueve firmemente en el silencio de la selva que abriga toda verdadera actividad creadora" (Thrall, 1965, p. 7). En esta figura del indio, se logra entrever también la resistencia al sentirse cómodo y al conformismo que encuentra seguridades en un significado simbólico en las pinturas. Lejos de esto, Magritte crea trampas, se niega a la interpretación absoluta y a la búsqueda de significados ocultos, quiere sí suscitar el misterio y el desconcierto para pensar de otro modo.

\section{Los juegos de la palabra y la imagen: lo enunciable y lo visible}

Dos son los referentes de los que partimos con el ánimo de ilustrar las relaciones entre lo enunciable y lo visible en René Magritte: el primero es el conocido ensayo sobre Magritte, escrito por Foucault: "Esto no es una pipa", en el que se aborda el problema estético expuesto por aquél en pinturas como $\mathrm{El}$ uso idiomático (1928-29) y Los dos misterios (1966). El segundo es una carta enviada por Magritte a Foucault que data de 1966.

Foucault (1981), en el ensayo sobre Magritte, recrea varias incertidumbres planteadas por éste en el dibujo de la pipa y el epígrafe "esto no es una pipa" quizá es la más importante relación entre texto e imagen. Lo desconcertante no es que exista una clara y punzante contradicción entre lenguaje e imagen, pues son dos planos diferentes de acceso a la realidad, pero que, no obstante, es inevitable relacionar el texto con el dibujo. Se trata de una relación descrita por Foucault en los siguientes términos: "en el caligrama actúan uno contra otro un "no decir todavía" y un "ya no representar" (Foucault, 1981, p. 38). De este modo, lenguaje e imagen pertenecen a sistemas diferentes e independientes, cuyo vínculo es fruto de una convención, con la que Magritte no está de acuerdo, que ve en las palabras y la representación visual meras reproducciones de los objetos. 
En la carta del 23 de marzo de 1966, escrita por Magritte a Michel Foucault, encontramos una explícita alusión a los juegos del pensamiento invisible que une las cosas tangibles y las imágenes visibles. Para Magritte, es la pintura la que hace que el pensamiento se haga visible, y esto en virtud de la semejanza, pues: "la semejanza no pertenece más que al pensamiento. Éste se asemeja convirtiéndose en lo que ve, escucha o conoce; se convierte en lo que el mundo le ofrece" (Magritte, 2003, p. 390). Lo visible, no obstante, puede ser tangible o intangible; lo primero, como es el caso de las cosas que ocultan otras cosas visibles; lo segundo, las imágenes pintadas que nada ocultan. Lo que pone de relieve el artista es que no debe concedérsele más importancia a lo invisible sobre lo visible o a la inversa, pues es ese juego entre lo visible y lo invisible lo que evoca el misterio de las cosas.

Con respecto a Foucault, lo que articula lo visible con lo invisible es un pensamiento, ya no formado exclusivamente por figuras pictóricas visibles, sino por un pensamiento cartográfico. Se trata de un pensamiento que levanta un mapa de lo visible o realidad misma por medio de lo que él denomina dispositivo, aparato o grilla por medio de la cual se inteligen problemas vinculados a las prácticas, pero, dispositivo, también es el conjunto de prácticas coherentes que organizan la realidad social. Siguiendo a Deleuze, para Foucault, un dispositivo, aparato o máquina es el resultado en el que determinadas prácticas, al articularse a regímenes de verdad, hacen ver y hacen hablar la realidad misma. Un dispositivo es la caja de herramientas con la que el pensador francés levanta una cartografía que le permite detectar las estrategias y tácticas ocultas por el saber, las normas, la verdad y las instituciones. Para autores como Dreyfus y Rabinow, el término dispositivo agrupa "discursos, instituciones, disposiciones arquitectónicas, reglas, leyes, medidas administrativas, enunciados científicos, proposiciones filosóficas, la moralidad, la filantropía, etc" (Hubert y Rabinow, 2001, p. 150).

Por otra parte, Deleuze, al describir las notas características del dispositivo, señala que "tienen, pues, como componentes líneas de visibilidad, de enunciación, líneas de fuerza, líneas de objetivación, líneas de subjetivación, líneas de ruptura, de fisura, de fractura que se entrecruzan y se mezclan mientras unas suscitan otras por medio de variaciones o hasta de mutaciones de disposición" (Deleuze, 1990, p. 159). En último término, un dispositivo es un ovillo o madeja vertebrada por las líneas mencionadas, pero que en ningún momento son una estructura cerrada y homogéneas que tienen la capacidad de transformarse y fisurarse.

\section{Obras caleidoscópicas}

Existen dos enfoques, igual de nefastos, que osan organizar a Foucault y a Magritte en una estricta secuencia cronológica con el contraproducente efecto de desdibujar su itinerario intelectual: el primero intuitivo, o de mirada del bosque, pasa por alto las transformaciones de la metodología de sus investigaciones, en el caso de Foucault, y de las técnicas pictóricas, en el de Magritte. El periplo intelectual de ellos, se aborda desde una visión de conjunto que, al querer abarcar de un solo golpe la extensión de sus obras, no repara en las rupturas y giros que entrañan la búsqueda estética y filosófica. En consecuencia, tal acercamiento cosifica sus obras, al concebirlas desde una exterioridad o cáscara vacía, que eleva a criterios de organización de las obras la pretendida, pero ingenua evolución temática y la unidad de método. Por otra parte, existe una segunda manera de abordar la trayectoria intelectual de estos dos personajes: la mirada del árbol. Aquí el temor de perderse en la enmarañada red de argumentos que despliegan las investigaciones de Foucault, y de extraviarse en el laberinto de imágenes y símbolos a los que recurre Magritte hace que se busque con desespero temas, teorías, objetos de estudio, categorías o frases, para el caso del filósofo. Mientras que para el pintor se pretende que coincida el título con el cuadro o se le busca una lógica racional. En fin, esta interpretación pretende tomar la punta de la madeja, capaz de desatar el nudo que implica la complejidad de tales obras.

La obra de Michel Foucault no debe ser entendida como un cuerpo sistemático de escritos estructurados de antemano, organizados a priori en virtud de una lógica consciente, sino un escenario caleidoscópico en el que los métodos, los problemas rastreados y las herramientas conceptuales han logrado ser expresados. De este problema de la organización es consciente Foucault, lo cual se evidencia en la vuelta permanente sobre asuntos que parecen trillados, y 
sobre los que insiste ${ }^{8}$. A manera de ejemplo, cuatro son las rupturas o discontinuidades que en Foucault se pueden destacar.

Así, por ejemplo, si bien es cierto que en los primeros trabajos que datan de 1954 Sueño $y$ existencia y Enfermedad mental y personalidad, Foucault respira de la atmósfera intelectual de su época por cuanto es influido por los psiquiatras de orientación fenomenológica, como Minkowski y Binswanger, fieles al método fenomenológico de Husserl. Dichos autores contribuirán a alejarlo de explicaciones positivistas, naturalistas y esencialistas que a la larga son nefastas para él, porque equiparan erróneamente la enfermedad mental a la orgánica. Por esto, a hombros de Minkowski, de orientación heideggeriana, Foucault se esforzará en ir del análisis fenomenológico al análisis existencial; sin embargo, aunque aquél suministre elementos importantes para el estudio de la enfermedad mental, como el medio espacio-temporal (Unwelt) y el medio-sociocultural (Mitwelt), es insuficiente por no estimar las condiciones externas y sociales generadas por el capitalismo. De allí que el pensador francés recurra a Marx. En consecuencia, el filósofo de Poitiers se sitúa más allá del ámbito trascendental y metafí-

8 No es el propósito de este escrito generar un recorrido por el extenso periplo filosófico y artístico del pensador francés y del pintor belga, sino de brindar un diagrama que sirva de mapa para quien luego desee introducirse en la lectura concienzuda de estos dos personajes.

Algunos intérpretes de Foucault suelen agrupar su trayectoria intelectual en torno a tres conjuntos de tópicos: el primero, consagrado al saber en relación con el análisis de los discursos. Al cual corresponden obras como La historia de la locura, Nacimiento de la clínica, Las palabras y las cosas, La arqueología del saber. El segundo, en el cual se encuentra una referencia explícita al asunto del poder, tiene por correlato: El orden del discurso, Vigilar y castigar, La voluntad de saber, entre otros, y, por último, el tercero, que se ocupa de la subjetividad y el problema del gobierno de los individuos. De allí forman parte: El uso de los placeres y El cuidado de sí, entre otros. Desde un ángulo similar, estudiosos de Foucault como Ana María Raggio (2002) abordan la extensa obra del filósofo desde distintos campos discursivos, los cuales corresponden a tres visiones 0 métodos: en primer lugar la arqueológica, localizada entre 1954 y 1969, entraña obras como Enfermedad mental y personalidad, así como Historia de la locura hasta Arqueología del saber. Un segundo campo discursivo es el genealógico, ligado al poder, abarcando obras como El orden del discurso, Nietzsche, la genealogía y la historia, Vigilar y castigar, La voluntad de saber, Defender la sociedad, Seguridad, territorio, población y Nacimiento de la biopolítica. Finalmente, para algunos de la gobernabilidad, el cual alude a la construcción de subjetividad, se trabaja en textos como el segundo y tercer volúmenes de Historia de la sexualidad. sico de la vivencia con el propósito de rastrear las condiciones históricas que por medio de prácticas modelaban la experiencia de la locura.

Nótese cómo un primer desplazamiento en la investigación del filósofo francés empieza a suscitarse cuando en su itinerario intelectual gira del análisis fenomenológico existencial a lo que erigirá en los sesentas como el método arqueológico. Esto no quiere decir que en la analítica del poder, que lleva a la anatomopolítica, no resuenen más los ecos de la fenomenología de Husserl, pues por medio de la influencia de la fenomenología de la percepción de Merleau Ponty -quien puso al cuerpo como centro de su reflexión- Foucault se apropia de una categoría importante de cara al estudio de la sociedad disciplinaria. De igual forma, aunque en cierto momento de sus estudios de la locura recurra a Marx, será necesario criticarlo posteriormente en la forma de la hipótesis represiva del freudo-marxismo cuando aborde el asunto del poder.

Ahora bien, una segunda ruptura en el periplo intelectual de Foucault es la ocurrida en el contexto del método arqueológico, entendiendo por éste no un método homogéneo y siempre orientado por una lógica a priori y consciente frente al objeto de estudio, sino como una herramienta que, a fuerza de rectificaciones y desviaciones, a manera de un caleidoscopio, se conforma a la luz de tres experimentos: Historia de la locura, Nacimiento de la clínica y Las palabras y las cosas. Sin abordar estas obras de manera pormenorizada, el análisis arqueológico encarado por Foucault encuentra su caldo de cultivo al hilo de los sesentas a la sombra del fenómeno estructuralista, así como de la historiografía francesa o Escuela de los Annales, pues, como lo anota Carlos Antonio Aguirre:

Si observamos el itinerario global de Michel Foucault, podremos darnos cuenta de que si bien todo su trabajo se aproxima y en ocasiones se vincula directamente con la historia, en cambio su conexión y su diálogo más explícito con la historiografía francesa, así como su intento de definición epistemológica respecto de ella, va a concentrarse de manera más intensa y determinante en la década de los años sesenta y más particularmente en el período que abarca de 1964 a 1971 (Aguirre, 1996, p. 221). 
No obstante, aunque pensadores importantes como Lévi-Strauss, Lacan, Althusser, Barthes y Deleuze influyeron en él, y una obra como Las palabras y las cosas haya sido tenida por muchos como el manifiesto del estructuralismo, también lo es que una obra como La arqueología del saber se interprete como un esfuerzo por alejarse del mismo.

Como puede advertirse, la tarea de construir un método arqueológico no fue una empresa exenta de dificultades, en virtud de las transformaciones y depuraciones del mismo, hasta el punto que un autor como Álvarez hable más bien de arqueologías:

Foucault estaba de hecho frente a dos arqueologías cuando se dispuso a sistematizar su método. No obstante, no le pareció así, y, como ya apuntamos, su idea era que un mismo método se había ido desarrollando progresivamente en esas obras (Álvarez, 1995, p. 92).

Ahora bien, el alcance de la arqueología ha sido trabajar con los discursos, en especial el de las ciencias del hombre, el cual es concebido como sujeto y objeto de saber. Por esto, la arqueología nos despierta del sueño dogmático de la antropología, pero pierde de vista el papel que juegan las estrategias y las tácticas que activan dichas prácticas discursivas. Es por esto que, a principios de los años setenta, bajo el influjo de Nietzsche y estudiando el asunto del poder, Foucault emplea el nuevo enfoque genealógico ${ }^{9}$.

La perspectiva genealógica se erige como un cambio radical en el horizonte metodológico, generado a la luz de conferencias, libros y cursos que suceden a su lección inaugural en el Collège de France. Entre los motivos de ese cambio se cuentan: la lectura de Nietzsche entre 1964 y 1968; el clima contestatario de mayo de 1968 y su militancia en el grupo de información sobre prisiones. Desde este escenario, Foucault acomete el asunto del poder, no como una teoría o concepto, sino como una práctica, ejercicio y estrategia que más que ser represivo, es

9 Lo genealógico se erige como un nuevo desplazamiento o ruptura que no implica necesariamente la anulación de lo arqueológico. No es el propósito investigar aquí las implicaciones de cada método, sino de ilustrar brevemente cómo el itinerario de Foucault entraña rectificaciones que a veces parecen no conducirle a parte alguna. positivo por cuanto produce realidad. Finalmente, un cuarto giro en las investigaciones de Foucault se suscita cuando su preocupación recae en el estudio de nuevas formas de producción de subjetividad al hilo de lo que denomina técnicas de sí, que apuntan a los placeres (aphrodisia), no para renunciar a éstos, sino para morigerarlos.

Por su parte, Thrall, codirector de la exhibición que realizara Magritte en el Museum of Modern Art de Nueva York en 1965, afirma con respecto a este artista que: "la exacta secuencia cronológica de los cuadros de Magritte es frecuentemente difícil de determinar, en la medida en que él ha tratado de relacionar estrechamente, aún idénticos temas, en intervalos diferentes" (Thrall, 1965, p. 13). De manera similar a Foucault en Magritte existen elementos que también permiten hablar de una obra caleidoscópica en la medida en que se encuentra en permanente transformación. Así, pues, estudiosos de Magritte, como Schneede (1973), suelen distinguir seis grupos temáticos: cuadros de tema detectivesco o de criminalística (Die Kriminalistischen Bilder), de collage (Die Collage-Bilder), lingüísticos (Sprach-Bilder), cuadros en el cuadro (Bild-Bilder), sobre metamorfosis (Verwandlungs-Bilder) y combinatorios (Kombinations-Bilder).

Sin pretender reducir los cuadros detectivescos, a una década en particular, hay una serie de ellos de los que Magritte se ocupa repetidamente en los años veinte. La voz de la calma (1928), El asesino amenazado (1926), El hombre con el periódico (1927) y El sonámbulo (1927), entre otros, se inspiran en los relatos y narraciones de Dashiell Hammet, George Simenon y de Edgar Allan Poe, quien, por boca de su personaje C. Auguste Dupin, observa en la minucia, en lo imprevisible y en el acontecimiento secundario la clave para el descubrimiento. En analogía con la novela detectivesca, el giro de una mirada, el cambio de una minucia en Magritte contribuyen a socavar el orden burgués. De allí, que para Benjamín, con quien Magritte se identifica en este punto, "la monstruosidad prolifera en las hendiduras y en los nichos de aquellos extraits de mille fleurs con los que la burguesía decora el mundo" (Konersmann, 1996, p. 14). Por esto es que hacia 1935 como premisa teórica de su periplo como pintor, Magritte sostenga: "Mi arte sólo vale algo en la medida en que se resiste a la ideología burguesa, en cuyo nombre se extingue 
la vida" (op. cit., p. 15). Ciertamente, en sus cuadros de tema detectivesco existe una predilección por lo misterioso y su impulso extra-artístico está vinculado también a una primera etapa surrealista en la que el uso de lo banal y trivial se articula a la intención de estos últimos.

Con respecto a los cuadros de collage y a diferencia de los detectivescos, se da una renuncia al discurso narrativo y a cualquier tipo de acción. En este contexto, el collage es definido por Max Ernst como "la explotación sistemática del encuentro, provocado casual o artificialmente, de dos o más realidades heterogéneas en un plano evidentemente inadecuado, y la chispa de poesía que salta al producirse el acercamiento" (Schneede, 1973, p. 27). Del mismo modo, el collage en Magritte debe entenderse en el sentido de ser tanto técnica como principio de estructuración de sus cuadros. Allí se da una combinación de elementos fragmentados de la realidad en la que en algunos existen motivos identificables; mientras que en otros, no o, simplemente, se da la ambivalencia. Los siguientes son cuadros de motivo collage: El jockey perdido (1926), La travesía difícil (1926), El nacimiento del ídolo (1926), El hombre del mar (1926) y La boda de medianoche (1926).

En los cuadros de motivación lingüística a diferencia de los demás surrealistas, el interés de Magritte es reflexivo. De esto da cuenta el cuadro La traición de las imágenes (1928-29), pues allí se presenta un problema pictórico de la relación entre lo representado y su representación en la que se aprecia una pipa acompañada del epígrafe: "esto no es una pipa". Se aborda el problema de la relación entre arte y realidad, una realidad desconcertante que, no obstante, da que pensar. En palabras de Schneede: "ni el lenguaje ni la representación visual son reproducciones; son sistemas instrumentales, medios con cuya ayuda y bajo cuyos presupuestos la realidad es representada en el plano de las apariencias" (op. cit., p. 40).

En cuanto a la producción artística, denominada bajo la expresión "cuadros en el cuadro", se subraya el problema, ya abordado en los lingüísticos, de la no identidad entre obra de arte y realidad en la que lo representado y la representación no son lo mismo. Ahora bien, el que un observador tome la imagen como semejante a la realidad es según Magritte: "porque los planos de la realidad (representado, representación) han sido necesariamente abolidos o se hallan más próximos a la ficción en el medio del cuadro. Tanto la copia (lienzo del caballete) como su modelo, son objeto de la representación. Ambos están sometidos a las leyes del cuadro" (op. cit., p. 48). Como ejemplos de obras que ilustran Los cuadros, en el cuadro, tenemos Los signos del atardecer (1926), La bella prisionera (1931), La condición humana I (1933), La clave de los campos (1933), La condición humana II (1935), entre otros. De igual manera, en este tipo de cuadros, Magritte aborda cuestiones relacionadas con la relación objeto y concepto, objeto e imagen y concepto e imagen. Con tales relaciones que, más que cerrar, abren hacia la interpretación, el pintor logra crear efectos subversivos.

En los cuadros sobre metamorfosis inspirados en Kafka; Magritte, siguiendo a los surrealistas, emplea el procedimiento de la metamorfosis de la transformación de un objeto en otro como constitutivo de la composición de cuadros. Así, el mismo Max Ernst habla de la imperiosa necesidad de emanciparse de experiencias y recuerdos fijos de un tedioso paraíso de manera que lo que hace la metamorfosis es ampliar el campo de la experiencia. Posibilidades pictóricas de ese intercambio de un ser humano en un pez, como en La invención colectiva; de un cuerpo femenino en rostro femenino como en La violación (1934); de unas botas en pies con dedos como en $\mathrm{El}$ modelo rojo (1935).

Finalmente, en lo combinatorio, no se trata simplemente de unir dos elementos contrapuestos o de dos realidades diferentes, tal como lo señala el espíritu del primer manifiesto surrealista de André Bretón en 1924, sino de una inversión o transgresión sutil, como por ejemplo un cambio de materiales como en la pintura El recuerdo de un viaje III (1951), en la que un comedor adquiere la solidificación del paisaje rústico que entre unas puertas también fosilizadas aparece como telón de fondo. En otras ocasiones se trata de un cambio en las proporciones, como en el cuadro Los valores personales (1951-52), en el que una serie de artículos cotidianos como un peine, un vaso, un espejo aparecen sobredimensionados ocupando una habitación. El pintor belga, con los cuadros combinatorios, suscita una contravención de la experiencia cotidiana, no para alejarse de ella sino permaneciendo cerca con el fin de sacudir el poder de la costumbre y la seguridad natural en 
el mundo. La combinación de fragmentos o de realidades, más o menos alejadas entre sí crea un chispazo como la anécdota de 1936, cuando, después de despertar, ve en una jaula un huevo en lugar de un pájaro: Las afinidades electivas (1936). 기

\section{Bibliografía}

Aguirre, C. (1996). Los Annales y la historiografía francesa. Tradiciones críticas de Marc Bloch a Michel Foucault. México: Editorial Quinto Sol.

Álvarez, J. (1995). Michel Foucault: verdad, poder, subjetividad. La modernidad cuestionada. Madrid: Ediciones Pedagógicas.

Deleuze, G. (1970). Lógica del sentido, Barcelona: Editorial Bote de Vela.

Deleuze, G. (1990). ¿Qué es un dispositivo? En Balbier, Deleuze; Dreyfus et ál., Michel Foucault, filósofo. Barcelona: Gedisa.

Fernández, B. (2000). Ver y leer a Magritte. Cuenca: Ediciones de la Universidad de Castilla-La Mancha.

Foucault, M. (1981). Esto no es una pipa. Barcelona: Anagrama.

Foucault, M. (1999). Estrategias de poder. Barcelona: Paidós.

Foucault, M. (2001). Defender la sociedad. Buenos Aires: Fondo de Cultura Económica.

Foucault, M. (2007). Nacimiento de la biopolítica. Buenos Aires: Fondo de Cultura Económica.

Habermas, J. (1989). El discurso filosófico de la Modernidad. Madrid: Taurus.

Handler, E. (1994). Museum of the mind: Magritte's Labyrinth and other essays in arts. New Haven y Londres: Yale University Press.
Hubert, D. y Rabinow, P. (2001). Michel Foucault: más allá del estructuralismo y la hermenéutica. Buenos Aires: Nueva visión.

Konersmann, R. (1996). La reproducción prohibida. México: Siglo XXI Editores.

Magritte, R. (2003). Escritos. Madrid: Editorial Síntesis.

Muchail, S. (2004). Foucault, simplesmente. Sao Paulo: Edições Loyola.

Paquet, M. (2000). Magritte. Köln: Taschen.

Raggio, A. (2002). Del poder del discurso al discurso del poder. Buenos Aires: Eudeba.

Schneede, U. (1973). René Magritte, leben und werk. Köln: Verlag M. DuMont Schauberg.

Thrall, J. (1965). Magritte. Nueva York: The Museum of Modern Art.

Torczyner, H. (1978). Magritte, signos e imágenes. Barcelona: Editorial Blume.

Vázquez, F. (1995). Foucault. La historia como crítica de la razón. Barcelona: Montesinos.

Veyne, P. (1984). Cómo se escribe la historia. Foucault revoluciona la historia. Madrid: Alianza Universidad. 